\title{
Más allá del medievalismo y el arabismo: Al-Ándalus en perspectiva poscolonial
}

\section{Beyond Medievalism and Arabism: Al-Andalus in a Postcolonial Perspective}

\author{
JAVIER GARCÍA FERNÁNDEZ \\ Universidad de Coimbra, Portugal
}

Resumen: El presente artículo pretende contribuir a superar las visiones eurocéntricas y occidentalistas del estudio sobre Al-Ándalus mediante el análisis crítico de dos disciplinas: el medievalismo y el arabismo. En la primera parte se describe el medievalismo como un ejercicio de occidentalismo; en la segunda se examina el arabismo español como una mirada proveniente del mundo colonial francés. Al final se incorporan algunas aportaciones de la teoría decolonial latinoamericana y de la corriente del medievalismo poscolonial anglosajón para situar ciertas líneas de análisis y reflexión que convocan a una mirada poscolonial y no eurocéntrica del fenómeno andalusí.

Palabras clave: medievalismo; arabismo; poscolonialismo; descolonización epistémica; Al-Ándalus.

Recepción: 9 de junio de 2020. / Aceptación: 8 de marzo de 2021.

D.R. ${ }^{\circ}$ 2022. Estudios de Asia y África Licencia Creative Commons Atribución-NoComercial-SinDerivar (CC BY-NC-ND) 4.0 Internacional 
Abstract: This article aims to contribute to overcoming the Eurocentric and Occidentalist views of Al-Andalus through the critical analysis of two disciplines: medievalism and Arabism. First, medievalism is described as an exercise in Occidentalism. Secondly, Spanish Arabism is analysed as a discursive corpus originating in the French colonial world. The text concludes by incorporating certain contributions from Latin American decolonial theory and from contemporary Anglo-American postcolonial medievalism, to locate certain lines of analysis and reflection that call for a postcolonial and non-Eurocentric view of the Andalusian phenomenon.

Keywords: medievalism; Orientalism; postcolonialism; epistemic decolonization; Al-Andalus.

\section{Introducción: ciencias sociales no eurocéntricas para una descolonización epistémica de Europa}

El presente artículo trata de dar continuidad a los esfuerzos intelectuales de la última década en torno a lo que se ha llamado la descolonización de Europa en el ámbito de las ciencias sociales y las humanidades. Desde diferentes perspectivas, autores como Boaventura de Sousa Santos (2019; y Sousa y Mendes 2017), Heriberto Cairo y Ramón Grosfoguel (2010), Grosfoguel (2011), Dispesh Chakrabarty (2008), Montserrat Galcerán (2016), María Paula Meneses (2011), Larisa Pérez Flores (2017 y 2018) y yo mismo (García Fernández y Moreno Colmenero 2015; García Fernández, 2016, 2018a, 2019a, $2019 b, 2019$ c y 2021) hemos trabajado en la producción de pensamiento crítico respecto al eurocentrismo desde la propia Europa para la descolonización epistemológica de las universidades occidentalizadas (Grosfoguel 2013). En este sentido, la propuesta que subyace en esta contribución trata de revisar críticamente el legado colonial castellanocéntrico y eurocéntrico de las miradas medievalistas y arabistas en torno a la historiografía sobre Al-Ándalus. Asimismo, recoge y ordena diferentes aportes de la teoría poscolonial (de la decolonial latinoamericana y del medievalismo poscolonial anglosajón) 
que nos permitan reformular una mirada crítica y autocentrada del fenómeno andalusí desde la sociedad andaluza actual y las sociedades del sur de Europa. Esto implica, inevitablemente, seguir abordando la descolonización interna de Europa, necesaria en el ámbito académico e intelectual español, donde las narrativas hegemónicas siguen ancladas a sectores vinculados al legado nacional-católico y colonial (García Sanjuán 2017; García Fernández 2021).

El motivo para proponer esta contribución tiene que ver con que, aún hoy, ninguna corriente poscolonial ha interpelado directamente el campo de los estudios históricos andalusíes. El silencio de Edward Said en su obra Orientalismo (2004) lo llevó a disculparse por haber evitado tomar posición en torno a la relación de España con su pasado andalusí. ${ }^{1}$ Tampoco los estudios poscoloniales del contexto africano, del mundo francés o anglosajón han llegado a interpelar de manera crítica el

${ }^{1}$ En la propia tradición intelectual española, autores como Américo Castro, Francisco Márquez Villanueva o Juan Goytisolo trabajaron a lo largo del siglo xx por cristalizar una explicación histórica que permitiera visibilizar la contribución oriental a las sociedades del sur de Europa, entre ellas la española y específicamente la andaluza. Estas contribuciones no fueron incorporadas por Edward Said a su trabajo. A pesar de que se ha dicho que posiblemente las conociera, seguramente problematizaban el esquema explicativo propuesto en Orientalismo. Tras muchas interpelaciones y preguntas desde diferentes ámbitos, no le quedó a Said más remedio que afirmar lo evidente. En el prólogo a la segunda edición en castellano de Orientalismo, editada y prologada por Juan Goytisolo, Said afirmaba: "Yo había dicho muy poco sobre la extremadamente compleja y densa relación entre España y el islam, que ciertamente no se podía caracterizar simplemente como una relación imperial. Desde 1978, y debido en gran parte a mi creciente familiaridad con la obra de Américo Castro y de Juan Goytisolo, he llegado a darme cuenta no sólo de cuánto hubiera deseado saber más acerca del orientalismo español mientras escribía mi libro durante los años setenta, sino de hasta qué punto España es una notable excepción en el contexto del modelo general europeo, cuyas líneas generales se describen en Orientalismo. Más que en cualquier otra parte de Europa, el islam formó parte de la cultura española durante varios siglos, y los ecos y pautas que perduran de tal relación siguen nutriendo la cultura española hasta nuestros días [...] Lo que estoy señalando aquí condena en cierto modo a mi libro por ignorar un episodio verdaderamente significativo en la poco edificante historia de las relaciones entre Oriente y Occidente, me gustaría sin embargo apuntar que, de cualquier modo, el lector español encontrará en estas páginas un contraste implícito entre lo que pasé tanto tiempo investigando, por un lado, y la tan diferente experiencia española, por otro" (Said 2004). 
estudio de Al-Ándalus. Tan sólo los autores de la llamada teoría decolonial latinoamericana han convocado, tangencialmente, a una discusión en torno al tema en relación con las conquistas americanas y la expansión moderna colonial, pero de forma limitada y sin haber tenido en cuenta la historiografía reciente sobre la cuestión andalusí.

Para el caso español, las universidades y las ciencias sociales no han sido sometidas a un análisis crítico que ponga de relieve el carácter colonial de las formas hegemónicas de conocimiento y las implicaciones epistemológicas que han acarreado las profundas imbricaciones entre ciencias sociales y proyecto colonial español. Esta contribución analiza principalmente las corrientes del medievalismo, ámbito de estudio del periodo medieval y feudal europeo, y del arabismo, área nacida desde los estudios orientales pero muy vinculada a la expansión colonial española en el norte de África (Marín 2014). Estas corrientes son, en la actualidad, dos de las que más investigación histórica hacen del fenómeno andalusí, sin por ello olvidar las importantes aportaciones de otras disciplinas, como la arqueología, la historia del arte, la arquitectura, los estudios literarios y otros campos de las humanidades. Lo que interesa comprobar es cómo, tanto en el medievalismo como en el arabismo, perviven significativos sesgos coloniales y eurocéntricos que determinan la manera de comprender el pasado de la península ibérica y, por lo tanto, de percibir históricamente el sur de Europa. Luego se revisa el escenario de la producción teórica del pensamiento decolonial latinoamericano y el medievalismo poscolonial anglosajón para destacar algunas reflexiones que podrían constituir nuevas y fértiles vías para abordar el pasado andalusí.

\section{E1 medievalismo como occidentalismo: consideraciones (pos)coloniales}

En la mayoría de las naciones europeas hegemónicas, las ciencias sociales contemporáneas han estado muy unidas a las ex- 
periencias de expansión colonial (Wallerstein 1996). Esto, que vale para el conjunto de las ciencias historiográficas de Europa occidental, no se ajusta del todo a la experiencia hispana (Lampert-Weissig 2010). Mientras que Francia o Inglaterra encontraron en las ciencias sociales nuevas herramientas intelectuales con las cuales explicar su expansión colonial, el caso español fue diferente. Las primeras corrientes historiográficas de marcado carácter científico surgieron en el primer tercio del siglo XX, tras la crisis terminal del Imperio español en 1898, y dieron lugar, por ejemplo, a la corriente intelectual conocida como la generación del 98. Las emergentes ciencias sociales en el caso español acompañaron la caída y el colapso del proyecto imperial y no su auge. Como señala Lisa Lampert-Weissig (2010, 27-28): "en España, no fue la incorporación y el sostenimiento de colonias, sino su pérdida y una sensación general de decadencia nacional lo que inspiró la búsqueda del sentido nacionalista entre los intelectuales y académicos de la 'generación del 98'”.

Los miembros de la generación del 98 se preguntan por el ser de España en clave nacional tras la descomposición del Imperio debido a la pérdida de las últimas colonias españolas en el Caribe y el Pacífico, y la retención de únicamente los territorios del norte de África. La traslación de este debate al ámbito de la historiografía la encontramos en el conocido enfrentamiento entre dos intelectuales republicanos, exiliados durante la dictadura militar franquista: Claudio Sánchez Albornoz, considerado pionero de los estudios medievalistas (Abellán 1993), y Américo Castro, conocido también por ser precursor del hispanismo (Guiance 2011; García Sanjuán 2005 y 2017). Se dio así una colisión entre dos perspectivas: una tesis integradora que reconocía el legado y la continuidad de Al-Ándalus en España (Castro 1954) contra una postura confortativa que lo negaba y que definía y construía lo español justamente como aquello que nace en ese proceso de conflicto y disputa contra Al-Ándalus (Sánchez Albornoz 1957). Es importante recordar que ambos historiadores desarrollaron su labor en el exilio, 
lo cual le dio a la discusión una fuerte matriz sentimental a la par que esencialista (García Sanjuán 2005, 143-153). Paradójicamente, la mirada esencialista de Sánchez Albornoz sería más tarde la versión oficial de la historia de España asumida por la historiografía y los intelectuales de la dictadura militar, a pesar de ser un debate iniciado en el exilio por uno de los últimos presidentes de la República española (Corral Lafuente 2009).

Para comenzar el análisis de los estudios medievales en relación con Al-Ándalus, hay que observar que el campo del medievalismo ha constituido cierta genealogía histórica de pertenencia que privilegia aquellos elementos del pasado que se consideran propios o que han sido tomados como antecedentes legítimos de las sociedades occidentales actuales (LampertWeissig 2010).

El medievalismo ha sido, en las facultades y los departamentos de historia del Estado español, la corriente intelectual mayoritaria y hegemónica que ha estudiado Al-Ándalus y su relación con la historia de España y, por tanto, de Andalucía. Además de Sánchez Albornoz como pionero de una determinada forma de entender y pensar Al-Ándalus y su incorporación a la Corona de Castilla tras las conquistas de los siglos XIII al xv, los referentes principales son Abilio Barbero y Marcelo Vigil Pascual (1994), Miguel Ángel Ladero Quesada (1969) y Eduardo Manzano (2006). En Andalucía, los modelos del medievalismo son Manuel González Jiménez (1988), Ángel Galán Sánchez (1991) y, en el ámbito de la arqueología, Manuel Acién Almansa (1994), además de muchísimos autores importantes y toda una tradición de producción historiográfica.

La construcción de las categorías, los marcos interpretativos, las cronologías y los elementos esenciales para el periodo medieval andaluz se establecieron en la década de 1980. Para definir en líneas generales esta corriente y, sobre todo, sus efectos en Andalucía se podría plantear que se trata de una visión de Al-Ándalus centrada en su incorporación a la Corona de Castilla. Los estudios medievales no han tratado de verlo como un fenómeno histórico en sí; más bien han centrado su 
análisis en el proceso de incorporación a la realidad castellana, a su estructura jurídica, militar, económica, social, cultural y administrativa. En lo relativo al estudio de la historia de Andalucía, atiende al año 711 como cierre de una parte de la historia de España, y no como transición, y pasa la página hasta 1212 para examinar las invasiones castellanas del valle del Guadalquivir y (a partir de la guerra de Granada 1482-1492) explorar la incorporación de Granada al reino de Castilla. Se trata de una mirada tanto de Al-Ándalus como de la sociedad andalusí que asume sinuosamente un locus de enunciación situado en las instituciones castellanas de la época, por lo que traslada una visión castellanocéntrica al estudio de Al-Ándalus. Es también una mirada que parte del proceso de incorporación de Al-Ándalus a la Corona de Castilla y, por tanto, del surgimiento de la Andalucía temprana en el ámbito de la monarquía hispánica. En última instancia, se trata de una razón histórica, de una forma castellanocéntrica de pensar y analizar el pasado. Es, además, una tradición historiográfica que se consolidó tanto cuantitativa como cualitativamente en las primeras décadas de la dictadura militar franquista y su nueva reconquista de la historia (Ríos Saloma 2011), con especial atención a la Hispania visigoda, la mal llamada (re)conquista y las repoblaciones castellanas. En definitiva, es una tradición histórica e historiográfica que explica España desde la experiencia de los reinos del norte y que, por tanto, muestra el sur de la península como la prolongación de los reinos cristianos en su proceso de conquista.

Quizás uno de sus representantes más actuales sea el historiador Rafael Sánchez Saus $(2017,186)$, quien afirma:

Lo cierto, aunque no siempre asumido, es que al-Ándalus, su significación y su legado cultural, dejaron de formar parte de la realidad de España y del horizonte de sus habitantes ya en el siglo xvi y de forma más plena y definitiva desde la expulsión de los moriscos entre 1609 y 1613, hace más de cuatrocientos años [...] la reivindicación de al-Ándalus forma parte hoy para muchos de la paralela puesta en cuestión e incluso negación de España. 
Dentro del medievalismo andaluz, quizá la voz crítica más reconocida sea la del historiador Alejandro García Sanjuán, quien ha abordado la influencia del nacionalismo español católico en las historiografías que se han desarrollado sobre Al-Ándalus. Según el autor: "La influencia del nacionalismo y del catolicismo permite comprender la forma en que Al-Ándalus ha sido caracterizada en el discurso historiográfico españolista” (García Sanjuán 2018, 40). Por otro lado, José Luis Corral Lafuente $(2009,413)$, otra reconocida voz crítica muy autorizada, plantea: "Afirmar que el medievalismo español de comienzos del siglo XXI es heredero del franquismo puede sonar demasiado fuerte, específicamente si se dice en voz alta y en una tribuna pública, pero no deja de ser cierto". El poder institucional volcado desde la dictadura franquista en las cátedras, institutos de investigación y planes docentes para el desarrollo de la investigación de la España medieval ha constituido la naturaleza del medievalismo español desde los primeros años de la dictadura hasta la actualidad (García Sanjuán 2017). Tal y como señala el historiador granadino Antonio Malpica $(2004,271)$ :

este reparto de papeles para el estudio de la Edad Media se ha hecho partiendo en el fondo [...] de una idea "ultranacionalista" en la que prima la concepción del "homo hispanicus", directamente heredero del sustrato ibérico, convenientemente romanizado y perfilado por los germanos. La esencia de lo hispánico ha configurado la Historia de España, lo que no es anormal con respecto a Europa, pero sí por el hecho de dejar a un lado la realidad de la sociedad andalusí.

En la misma tradición de historiadores marxistas en la que se sitúa Antonio Malpica, encontramos una de las grandes referencias del medievalismo europeo, Chris Wickham (2009, 91-92), quien analiza el comportamiento de la historiografía españolista respecto a Al-Ándalus y observa: "La época árabe es un punto de atención crucial en el debate, ya que su legítima posición en la ininterrumpida relación con la memoria histórica española (cristiana) ha sido siempre disputada [...] Suprimir 
el periodo árabe ha sido una solución, en particular entre los conservadores de distintas ideologías".

\section{Arabismo, segundo Imperio francés y colonialismo español en África}

La otra corriente científica que ha estudiado en profundidad el hecho andalusí como fenómeno histórico es el arabismo. Se trata de una disciplina que ha investigado fundamentalmente la lengua, la literatura y la cultura del mundo arabo-musulmán, la realidad social del mundo árabe actual, el islam como hecho religioso y la historia del islam como civilización (González Ferrín 2015). En origen, fue esencialmente francesa, y por coyunturas compartidas se desarrolló también en el Estado español (Fernández Parrilla 2018).

$\mathrm{El}$ arabismo es la forma específicamente hispanofrancesa de lo que Edward Said llamó orientalismo. Surgió en el siglo XIX, a partir de la nueva fase del imperialismo nacida con el segundo Imperio colonial francés en 1830, durante la conquista de Argelia (Hobsbawm 1998). En la segunda mitad del siglo xIX, Francia había conquistado los territorios de las actuales Vietnam y Camboya, y en 1881 instauró el Protectorado de Túnez. La Conferencia de Berlín de 1884 repartió África entre las principales potencias europeas, sobre todo Francia, Alemania, Bélgica, Reino Unido y, en menor medida, Portugal, Italia y España. El arabismo nació en el contexto de la intervención colonial hispanofrancesa en el norte de África. La consolidación y el avance colonial europeo en África (en el Magreb para el caso que nos ocupa) dio lugar a que en los países occidentales se afianzara un nuevo espacio de investigación sobre historia y cultura del mundo arabo-musulmán. En el caso del arabismo francés, son muchos los autores que han demostrado cómo las administraciones coloniales tuvieron que ir incorporando al mismo tiempo instituciones para el estudio, la comprensión y la posibilidad de interlocución con las sociedades colonizadas (Marín 2014). 
Sin duda, el arabismo español tuvo una particularidad ajena al francés: no se enfrentó sólo a un sujeto extraño, colonizado, al que debía comprender y dominar según los intereses de la metrópoli; se encontró ante un viejo conocido, el legado andalusí. Un legado cultural propio que, sin embargo, fue analizado por la naciente disciplina como una exterioridad a la historia de España y desde una perspectiva profundamente colonial, como se ha señalado en otro trabajo (López García 2011; Marín 2009; Aziza 2017). En virtud de que eran los únicos especialistas científicos conocedores de la lengua árabe, los arabistas españoles, durante todo el siglo Xx, no escaparon a la necesidad de explicar también el pasado árabe de la península.

En este sentido, además de Emilio García Gómez (19051995) (quizás el mayor arabista español del siglo Xx), debemos citar de forma obligada a Pedro Martínez Montávez (1994), Serafín Fanjul (2014) y María Jesús Viguera Molins (1992) como las autoridades en el estudio histórico de Al-Ándalus desde el arabismo. En su caso, y en el de la mayor parte de los investigadores en el área, hablamos de especialistas en filología, literatura, historia y cultura árabe que, por lo general, estaban al margen de los avances y los debates en historiografía social y económica (Molina 1992). Esto generó una mirada histórica sobre el hecho andalusí atravesada por estudios sobre historia de la literatura y de la lengua árabe. Al ser la fuente privilegiada las crónicas y la literatura, tenemos una historia de Al-Ándalus muy lingüística, es decir, filológica y en exceso literaria, contada como crónica o como mero comentario de las crónicas (García Sanjuán 2001; Marín 2014; García Contreras, Martínez Vázquez y Villar Mañas 2012).

Otro hecho importante para comprender el arabismo español y su mirada histórica tiene que ver con que, en el ámbito francés, también surgió una corriente que estudiaba Al-Ándalus como proyección o prolongación del mundo arabo-islámico actual (López García 2016), y trasladó a su interpretación la mayor parte de los parámetros culturales, étnicos, organizativos y etnológicos que la mirada colonial francesa observó en el 
mundo árabe contemporáneo (Marin 1992). Esta tradición está representada por Pierre Guichard y se consolidó con su obra culmen Al-Andalus: estructura antropológica de una sociedad islámica en Occidente (Guichard 1976), pero se inauguró ya en el XIX con otros importantes autores como Reinhart Dozy, Evarist Lévi-Procençal y, en la primera mitad del siglo xx, con Henri Pérès o Henri Terrasse (Marín 1992). La influencia del arabismo francés sobre el español ha sido, sin duda, crucial e importantísima, pues ha atravesado radicalmente su forma de interpretar Al-Ándalus, en especial al establecer el centro del análisis en términos de berebización y arabización, es decir, al comparar la sociedad andalusí con las sociedades actuales del mundo árabe y musulmán. Las investigaciones y las publicaciones sobre la interpretación histórica de Al-Ándalus han tratado de historiar el islam como hecho religioso o civilizatorio, porque se ha pensado Al-Ándalus desde la religión o desde el mundo arabo-musulmán actual.

Como plantea Antonio Malpica $(2004,265)$, historiar AlÁndalus supone "acabar con la división entre medievalistas y arabistas, y deben de concurrir ambos en el campo de la historia, en algunos casos como actores principales, en otros como secundarios”. ¿Qué aportan en conjunto? ¿Qué le falta a ese conjunto?

\section{Al-Ándalus en perspectiva poscolonial: contribuciones al desarrollo de una apertura crítica}

A continuación se desarrollan algunas estrategias teóricas en torno a una visión poscolonial de Al-Ándalus, es decir, un nuevo paradigma de estudio del periodo y del fenómeno andalusí. El objetivo es construir una mirada histórica y un marco de interpretación diferente, en el contexto de las producciones poscoloniales (Pérez Flores 2017 y 2018). En las últimas décadas, pensadores y pensadoras que provienen de procesos de descolonización y de ciertos ámbitos académicos críticos han for- 
mulado de otro modo el carácter eurocéntrico y colonial de las ciencias sociales y las humanidades en las universidades occidentalizadas (Grosfoguel 2013) y convocan a construir un paradigma que vaya más allá del canon hegemónico, capaz de reconocer la diversidad epistemológica del mundo.

Como aclaración conceptual, en la línea propuesta por Larisa Pérez Flores (2017), llamo producciones poscoloniales al conjunto de formulaciones críticas (tanto académicas como literarias, artísticas, políticas o intelectuales) que trata de revisar el legado del colonialismo y el eurocentrismo en las ciencias sociales y las humanidades contemporáneas, elaborado tanto en el contexto de las luchas anticoloniales de los periodos posteriores a las independencias como en los contextos de colonialismo interno (González Casanova 2006). En cambio, el paradigma poscolonial es el conjunto de corrientes intelectuales críticas con el colonialismo y el eurocentrismo, como los estudios subalternos de India, la crítica orientalista, el marxismo afrocaribeño, las filosofías andinas, el pensamiento fronterizo chicano, el giro decolonial latinoamericano, los feminismos descoloniales o las epistemologías del sur. Cada una de estas corrientes encuentra su propia especificidad, su matriz crítica y su ámbito disciplinar e intelectual, pero es posible agruparlas en un amplio espacio conceptual: el paradigma poscolonial.

Muchas son las transformaciones, las disputas y las tensiones que han afectado el conjunto de las ciencias sociales y las humanidades desde las publicaciones, en 1979, de Orientalism (2004), del palestino Edward Said; Women, Race and Class (1981), de la afroamericana Angela Davis; Subaltern Studies II: Writings in South Asian History and Society (1983), del indio Ranajit Guha; Introducción a la filosofía de la liberación, del latinoamericano Enrique Dussel (1983); Borderlands/La Frontera: The New Mestiza, de Gloria Anzaldúa (1987), o Decolonising the Mind: The Politics of Language in African Literature, del keniata Ngugi Wa Thiong'o (1987). En el campo de los poscolonialismos convergen diferentes corrientes críticas que tratan de producir conocimiento desde la diferencia colonial (Mignolo 
2008) y desde el otro lado de la geografía de la razón (Grosfoguel 2008 y 2016), confrontando así los legados culturales y las formas de dominación intelectual de los proyectos coloniales originados en la expansión occidental por el mundo que se instalaron en las instituciones académicas, universitarias y de educación superior internacionales. El colonialismo intelectual (Fals Borda 1987), la colonialidad del saber (Lander 2000) o el imperio cognitivo (Sousa 2019) hacen referencia a las formas de dominación cultural y a las estructuras epistémicas que el colonialismo y la dominación imperialista han consolidado en las universidades de todo el mundo.

\section{Contribuciones desde América Latina para pensar Al-Ándalus y el sur de Europa}

Vale la pena destacar las contribuciones que desde la teoría decolonial latinoamericana han hecho estudiosos como Ramón Grosfoguel (2013), Fernando Coronil (1998), Enrique Dussel (1994) o Walter Mignolo (2003), por la cercanía que supone la teorización latinoamericana en torno a procesos históricos que fueron compartidos en el proyecto imperial hispánico. Me refiero a la experiencia de 1492, año de la toma castellana de Granada y de la llegada de los conquistadores castellanos al Caribe y a América Latina. Las discusiones latinoamericanas en torno a la conquista, al mal llamado "descubrimiento", y la construcción de sociedades desde la violencia colonial suponen una contribución de primer orden para abordar la cuestión andalusí. Pensar las ciencias sociales andaluzas desde un reconocimiento epistémico que recoja la diferencia colonial y las historias locales (Mignolo 2003) es enormemente relevante para abordar nuevas investigaciones que piensen la experiencia histórica andalusí más allá de los legados eurocéntrico y castellanocéntrico.

La primera aportación del pensamiento decolonial latinoamericano tiene que ver con las interpretaciones sobre 
Al-Ándalus construidas en lo esencial desde una perspectiva ajena a su propio centro de gravedad, como lo es la sociedad andaluza actual y las experiencias históricas mediterráneas y del sur de Europa. Como señala Mignolo $(2003,21)$, producir “en y desde las historias locales a las que les fueron negadas potencial epistémico y, en el mejor de los casos, fueron reconocidas como 'conocimiento local' o localizado". En el mismo sentido el autor señala:

La crítica y la teoría poscoloniales tienen, entre una tarea posible, ganar lo que fue negado por la occidentalización (entendida como "expansión del lugar de enunciación”). Esto es, construir nuevos lugares legítimos de enunciación que hagan posible la re-locación de las construcciones imaginarias (Oriente, extremo Occidente), producida expansión occidental, por el crecimiento monstruoso de la creencia de que el lugar de enunciación es sólo uno, el de Occidente (Mignolo 1995, 39).

Es oportuno recoger una segunda contribución de la teoría latinoamericana que trata de poner en relación la mirada intelectual del medievalismo español con lo que el venezolano Fernando Coronil $(1998,132)$ ha definido como occidentalismo en su obra Más allá del occidentalismo: hacia categorías geobistóricas no imperialistas:

Se trata de un conjunto de prácticas representacionales que participan en la producción de concepciones del mundo que 1) dividen los componentes del mundo en unidades asiladas; 2) desagregan sus historias de relaciones; 3) convierten la diferencia en jerarquía; 4) naturalizan esas representaciones; y 5) intervienen, aunque sea de forma inconsciente, en la reproducción de las actuales relaciones asimétricas de poder.

En palabras de Coronil (1998, 12): “el 'occidentalismo', a diferencia del 'orientalismo', es el discurso de la anexión de la diferencia más que de la creación de un opuesto irreductible”. En este esfuerzo de ir más allá de las teorizaciones del occidentalismo, Enrique Dussel ha abordado una nueva filosofía de la historia mundial que trata de reconstruir un diálogo entre las experiencias históricas del mundo más allá de la historia univer- 
sal eurocéntrica. Una de sus propuestas es revisar críticamente las periodizaciones de la historia universal en relación con los procesos históricos internos europeos, en especial del periodo medieval (Dussel 2007), como una fase previa de oscuridad que antecedió al supuesto despertar de la humanidad a la modernidad occidental. En la construcción de una nueva periodización, debemos sentirnos interpelados desde el sur de Europa, pues, como plantea Dussel $(2007,88)$ :

la civilización musulmana nunca tuvo una Edad Media, ni una Edad oscura, ni feudalismo. La Edad Media europea fue para el islam su Edad clásica, su Modernidad. Nació como una civilización mercantil, urbana, de grandes proyecciones geopolíticas que llegó a unir, dos siglos antes de la invasión europea de América, el océano Pacífico con el Atlántico.

Es relevante valorar las reflexiones producidas desde América Latina que contribuyen a pensar de otra forma la historia del mundo y superan las periodizaciones clásicas de la historiografía eurocéntrica. Otra contribución para pensar la experiencia andalusí es la obra ya clásica 1492. El encubrimiento del Otro. Hacia el origen del mito de la modernidad (Dussel 1994), que recopila las conferencias que el autor impartió como invitado en la Universidad de Sevilla, convocadas como homenaje crítico del quinto centenario de las conquistas americanas. En el prólogo de su obra, Dussel $(1994,12)$ señala:

Quiero dejar constancia que escribo estas Palabras Preliminares aquí en Sevilla, al comenzar la redacción de estas conferencias. Esta, que fue tierra de moros, de musulmanes hasta aquel trágico 6 de enero de 1492 en que los Reyes Católicos ocuparon la refinada Granada, entregada por Boabdil, el último sultán que pisó tierra europea, como término final de la Edad Media [...] Así como los cristianos ocuparon Málaga [...], cortando a cuchillo las cabezas de los andaluces musulmanes en 1487, así también les acontecerá a los "indios", habitantes y víctimas del nuevo continente "descubierto". Alianzas y tratos nunca cumplidos, eliminación de las élites de los pueblos ocupados, torturas sin fin, exigencias para que traicionen a su religión y cultura bajo pena de muerte o expulsión, ocupación de tierras, repartimiento de los habitantes en manos de los 
capitanes cristianos de la "Reconquista". El "método" violento se experimentó durante siglos aquí, en Andalucía. La violencia victimaria y sacrificial pretendidamente inocente inició su largo camino destructivo.

Pero si hay un autor de la teoría decolonial latinoamericana que ha contribuido al estudio crítico del periodo andalusí ha sido Ramón Grosfoguel. Dos son sus aportaciones que debemos señalar. En primer lugar, "Las múltiples caras de la islamofobia" (2014) y "Racismo epistémico, islamofobia epistémica y ciencias sociales coloniales" (2011) son centrales para comprender la forma en la que las ciencias sociales contemporáneas han definido los fenómenos culturales e históricos del mundo árabe y musulmán. Además, agrega ciertas claves para comprender por qué los fenómenos históricos y culturales árabes e islámicos internos de la propia historia de Europa han sido silenciados, negados y constantemente subinvestigados. La segunda contribución la encontramos en su trabajo "Racismo/sexismo epistémico, universidades occidentalizadas y los cuatro genocidios/epistemicidios del largo siglo Xvi” (2013), donde combina la teorización de Boaventura de Sousa Santos de genocidios epistémicos de la modernidad (Sousa 2016) con la propuesta de Enrique Dussel de las premisas filosóficas de la modernidad de ego conquiro, ergo sum (conquisto, luego existo), en las que incluye la conquista de América y la de África (Dussel 2008). Ramón Grosfoguel (2013) incorpora la conquista de Al-Ándalus y el feminicidio de las brujas en Europa, de forma que conecta la experiencia andaluza con el escenario de discusiones decoloniales en América Latina, el Caribe, el mundo arabo-musulmán y África. Pensar históricamente los procesos de conquista de Al-Ándalus en relación con el preludio de las conquistas americanas y desde las propuestas teóricas y filosóficas nacidas en otras sociedades fruto de esos mismos procesos de conquista, los conecta con otros debates intelectuales que amplían el canon de comprensión de Al-Ándalus más allá de las miradas hegemónicas europeas que observan el fenómeno andalusí como algo exterior a la experiencia europea. En este 
sentido, la teoría de la decolonialidad latinoamericana y las discusiones sobre la dimensión colonial de la modernidad (Grosfoguel 2011; Dussel 1994) pueden incorporar contribuciones novedosas para pensar las conquistas de Al-Ándalus en el proceso de conformación de la modernidad temprana en el sur de Europa.

De igual forma, hay que señalar las evidentes limitaciones de la decolonialidad latinoamericana para abordar el estudio histórico de un fenómeno de la complejidad de Al-Ándalus. Coincido con Sousa Santos en sus críticas a la corriente latinoamericana (Sousa y Sena Martins 2018), cuando señala, entre otras cosas, un fuerte americanocentrismo que aleja esta corriente de fenómenos africanos o asiáticos. Destaca, además, en relación con la corriente decolonial latinoamericana, una fuerte actitud antiacademicista que trata de sustituir los saberes producidos en las universidades por una suerte de saberes populares, sin reconocer la diversidad de formas de saber y de conocer el mundo de las tradiciones intelectuales académicas de diferentes territorios no occidentales. En este sentido, me atrevo a formular una nueva crítica derivada de la dimensión ahistórica de la producción decolonial latinoamericana. La ausencia de historiadores y el que no hayan incorporado los recientes avances historiográficos hacen muy frágiles las contribuciones de dicha corriente. Al concepto de colonialidad propuesto como fenómeno constitutivo de la modernidad, el capitalismo y el racismo, que surge con la conquista de América en el año 1492 (Quijano 2000; Mignolo 2000), le falta una mayor profundidad histórica para explicar esos procesos según geografías y temporalidades que no siempre son homogéneas. En todo caso, a la luz de la globalización temprana (Hausberger 2018), sabemos que la expansión colonial en el mundo ibérico e hispanocolonial comporta una complejidad por la cual fenómenos como el capitalismo, el racismo o el colonialismo no son en ningún caso simultáneos ni espontáneos, sino que responden a procesos complejos y dispares que toca estudiar específicamente de forma local, pero situados en el contexto histórico de esa primera 
globalización temprana. La falta de una visión histórica en los autores decoloniales latinoamericanos (mayoritariamente) les hace obviar, por ejemplo, la aparición de las políticas de raza en la conquista de Granada (Barrios Aguilera 2007) o la génesis del capitalismo mercantil en la crisis del Mediterráneo en los siglos XIV y XV (Braudel 2015). El desarrollo teórico de la colonialidad se ha producido como formulación ahistórica, cuyo desarrollo no se ha narrado y explicado históricamente. La corriente decolonial latinoamericana se muestra así conceptual e historiográficamente insuficiente. Considero fundamental entender que el reto de las próximas décadas será pensar históricamente, con estudios más específicos en torno a periodos más concretos, la relación entre la conquista de Al-Ándalus, la colonialidad, la génesis del capitalismo y la clasificación racial en el contexto de la primera mundialización (Gruzinski 2016) y de la globalización temprana (Hausberger 2018).

\section{El medievalismo poscolonial anglosajón como crítica bistoriográfica poscolonial en Europa}

Desde otra perspectiva y desde otra latitud, en la última década han sido numerosos los trabajos que proponen una nueva revisión crítica de la historiografía medievalista europea. Un campo en el que se han desplegado los imaginarios coloniales a partir del siglo XIX y donde se han proyectado las narrativas imperiales modernas y contemporáneas tratando de construir un armazón teórico e historiográfico que justifique la posterior supremacía europea y occidental. La corriente del medievalismo poscolonial remite a una nueva revisión del periodo medieval europeo que concentra sus esfuerzos en analizar los antecedentes medievales de los grandes fenómenos históricos del periodo moderno, como la expansión medieval, la formación del capitalismo histórico o la génesis de los nacionalismos (Gaunt 2009; Cohen 2000; Lampert-Weissig 2010; Ganim 2016; Dagenais y Greer 2000; Bartlett 2001; Altschul 2009; Holsinger 2002). 
Este carácter occidentalista del medievalismo español, tanto del siglo XIX como del XX, también ha sido discutido desde el medievalismo poscolonial anglosajón, que destaca el aporte de los estudios poscoloniales para desoccidentalizar y descolonizar los estudios medievalistas, además de los límites de la disciplina nacionalista del siglo XIX (Altschul 2009). En este sentido, señala Simont Gaunt $(2009,172)$ :

La teoría poscolonial nos da una mejor comprensión de cómo surgió Europa, cómo se relacionó con el resto del mundo o cómo fue el contacto del periodo medieval entre Europa y Asia o África, ya que, de hecho, son elementos importantes para comprender una historia más larga de la cual el colonialismo y el periodo poscolonial son parte.

En lo que respecta a esta discusión, el territorio de conquista que nos concita como objeto de estudio es el pasado en sí, es decir, la forma de conocer, interpretar y narrar los acontecimientos sucedidos en el pasado, entendido como un lugar de disputa donde historiadores y académicos proyectan los valores y los consensos de su época. Como señalan Dagenais y Greer $(2000,438)$, tenemos que comprender que "la Edad Media ha sido una región colonizada al interior de la propia historia de la modernidad". Ambos autores continúan su reflexión de la siguiente forma:

La colonización del pasado ha acompañado siempre la construcción del proyecto imperial. Al mismo tiempo que los imperios europeos se establecían en vastos espacios geográficos, se reconfiguraban desde una compleja y simultánea asimilación/negación de dichos espacios y de las personas que los habitaban. Al mismo tiempo también, los proyectos imperiales involucraron estos territorios en la invención de un nuevo pasado común, pese a que a los colonizados nunca se le fuese a otorgar la ciudadanía de la nación de la modernidad (Dagenais y Greer 2000, 431).

Como también señala Lisa Lampert-Weissig (2010, 28-29): "La relación entre el colonialismo y el medievalismo es muy relevante en la discusión sobre las colonias internas de Europa"; 
o Bruce W. Holsinger (2002, 1200): "El reciente encuentro entre los estudios poscoloniales y los estudios medievales ha dado lugar a nuevas líneas de investigación en torno a la naturaleza premoderna del colonialismo y el imperialismo".

La perspectiva medievalista poscolonial propone formas de pensamiento desde - y en torno a- sociedades que han sido históricamente concebidas como interesante material etnográfico, pero no como productoras de teoría desde su específica condición. Jeremy Cohen (2000, 4-8), miembro también de la corriente del medievalismo poscolonial británico, señala:

La teoría poscolonial ha instado desde hace mucho tiempo a una perspectiva crítica contextualizada geográfica, cultural e históricamente. Una perspectiva crítica que ha analizado y desentrañado la colonización imperialista del espacio debe pasar ahora a examinar las colonizaciones epistemológicas del tiempo [...] El tiempo y la historia están siempre colonizados y nunca son una otredad inerte e inocente que espera ser excavada. Debido a que tomamos como punto de partida la descolonización de "Europa" desde dentro y empleamos modos de análisis discursivos sobre otras posibles metodologías, las contribuciones del medievalismo poscolonial precisan enfatizar la heterogeneidad interna de Occidente y la fantástica construcción textual de Oriente.

El autor sostiene que el medievalismo ha sido una disciplina para estudiar los elementos considerados autóctonos, a partir de los cuales se hacía una genealogía hacia el presente de la Europa occidental. Mientras, a través de los estudios orientales (como el arabismo) se han analizado aquellos seres que, pese a compartir territorio, eran señalados como extranjeros y extraños, constitutivos de alteridad.

El medievalismo poscolonial británico no sólo ha contribuido a una nueva visión del periodo medieval inglés en particular, y del europeo en general, sino que también ha destacado la importancia de llevar esta perspectiva al campo de los estudios medievales ibéricos. En su trabajo “The Future of Postcolonial Approaches to Medieval Iberian Studies”, la historiadora Nadia R. Altschul señala: 
Vale la pena subrayar la necesidad de que un enfoque poscolonial en el medievalismo debe incluir también a la península ibérica [...] Desde mi punto de vista, tanto el futuro de los enfoques poscoloniales como una incorporación adecuada de la España medieval a la discusión académica han de incorporar nuevos conocimientos teóricos en la disciplina [...] A pesar de la influencia de Castro, el reconocimiento de la presencia semítica y de las condiciones multiculturales de la península no ha dado lugar a una discusión desde enfoques poscoloniales (Altschul 2009, 13).

Desde las contribuciones que aporta el medievalismo poscolonial británico, debemos afrontar los retos del estudio histórico y sociológico del periodo andalusí en las universidades andaluzas y españolas, para dejar de ser un lugar cuya historia se estudia, y comenzar a ser un lugar desde el que se produce conocimiento. Me parece relevante señalar la necesidad de construir esta nueva teoría historiográfica, ya que puede aportar un significado específico a nuestra realidad histórica y a nuestra experiencia como sociedades, más allá de los cánones del medievalismo que privilegia lo que nos define como occidentales o que, por todo lado, nos sitúa en la experiencia feudal europea.

Dagenais y Greer $(2000,439-440)$ ubican su propuesta crítica en periodo andalusí y los estudios medievales del contexto ibérico señalando: "Los medievalistas españoles a menudo sienten que trabajan bajo una doble colonización: la representada por la condición colonizada de la Edad Media y la que surge del papel dominante del norte de Europa, especialmente de Francia e Inglaterra, en la colonización de la disciplina de los estudios medievales".

Más allá de ciertas contribuciones relevantes del medievalismo poscolonial británico para reinterpretar Al-Ándalus, no se trata de repetir mecánicamente los razonamientos de dicha corriente, pues estaríamos reproduciendo de nuevo los cauces del colonialismo intelectual (Fals Borda 1987), la colonialidad del saber (Lander 2000) o el imperio cognitivo (Sousa, 2019) que tratamos de superar. Es importante, por lo 
tanto, marcar distancia con los emergentes debates teóricos anglosajones, ya que la experiencia andalusí es ajena al feudalismo noreuropeo (Acién Almansa 1994; González Ferrín 2019), pues introduce nuevas categorías, como los modos de producción orientales, asiáticos y urbanos, que conectan los territorios del sur de la península ibérica con los ciclos civilizatorios mediterráneos. Además, las miradas que pretendan abordar las colonialidades internas del sur de Europa deben partir de una posición epistémica y de un locus de enunciación que trascienda a las sociedades vencedoras. Las experiencias del mundo árabe, islámico, morisco, bizantino y otomano en Europa parten de posiciones que han sido expulsadas o marginadas de las narrativas hegemónicas de la historia de Europa y de la historia "universal".

\section{Pensar la cuestión andalusí en perspectiva poscolonial:} hacia nuevos paradigmas teóricos no eurocéntricos desde el sur de Europa

Desde diferentes perspectivas, asistimos a un renacer de las miradas poscoloniales que comienzan a tener el sur de Europa y su relación con el norte de África como centro de la renovación intelectual. Las recientes publicaciones en (o sobre) el ámbito andaluz (González Ferrín 2019; González Alcantud 2021; González Alcantud y Rojo Flores 2014; Calderwood 2018; García Fernández 2019a; García Contreras 2021) constatan este tránsito de la reflexión poscolonial y en todas aparece la búsqueda de un nuevo locus de enunciación que supere el centro epistémico tradicionalmente situado en las experiencias del norte de Europa o de los países occidentales.

Si se asume que el medievalismo español historiza la experiencia andalusí desde la visión histórica de los reinos cristianos del norte de la península ibérica, y que el arabismo, por otro lado, lo hace desde el contexto actual del mundo arabo-islámico, se observa que Al-Ándalus ha sido explicado por sus conquista- 
dores desde una perspectiva profundamente castellanocéntrica o, por otro lado, desde aquellos que creen haberla perdido, esto es, el mundo arabo-islámico actual (visión muy anclada en las universidades francesas). Fruto de esta problematización, las categorías de interpretación de Al-Ándalus, como invasión, conquista, tribalización, bereberización, Edad Media, feudalismo, arabización e islamización, hacen referencia a procesos de aculturación, de integración a sistemas geopolíticos o culturales, así como a categorías que responden a experiencias históricas procedentes de otras latitudes, concretamente del norte de Europa y del norte de la península ibérica.

La contribución que propongo sitúa la etapa de Al-Ándalus como uno de los periodos esenciales de la historia de Andalucía, del sur de Europa y del mundo mediterráneo. Al-Ándalus no es sólo la frontera que la Europa cristiana feudal y medieval encuentra con el mundo arabo-musulmán, sino que, como sociedad de frontera, su condición está atravesada por una perspectiva que entiende también lo fronterizo como una comunidad que se constituye a sí misma como centro de su propia experiencia.

Para abordar la cuestión andalusí desde una nueva lectura que entienda la conquista del sur de Europa como preludio de la expansión colonial, debemos ir más allá de las historiografías centro-periferia para analizar los contactos mediterráneos, africanos y asiáticos que se condensan en el sur de la península ibérica y que son primordiales para comprender el patrón del poder colonial que se hace mundial con la expansión ibérica en el Caribe y en América Latina (García Fernández, 2018b y 2021).

Así pues, el esfuerzo intelectual que propongo no es concluyente, sino que trata de inaugurar una serie de reflexiones históricas, analíticas y epistemológicas que construyan nuevos marcos de interpretación del periodo andalusí. El pasado árabe del sur de Europa no se explica nada más con las categorías planteadas por el medievalismo y el arabismo. Debemos explicar experiencias históricas más amplias, como el feudalismo en la península ibérica, el desarrollo del islam en 
Europa y la génesis y la formación del capitalismo en el sur de Europa desde lo que Emilio González Ferrín (2019) propone como el paradigma Al-Ándalus. Urge una renovación conceptual en relación con las categorías básicas y los marcos desde los cuales se analiza la cuestión. En segundo lugar, una interpretación poscolonial sobre Al-Ándalus lleva a una discusión más amplia sobre el sur de Europa. En el escenario de investigación actual, se requiere renovar la periodización del estudio del sur de Europa entre los siglos viII y XVI, reformulando lo que tradicionalmente se llama 'Edad Media' como periodo de interludio o crisis. Esta categoría, que da lugar al medievalismo, a los estudios medievales, a la conceptualización del feudalismo, vale sólo para los territorios del norte de Europa y no tiene capacidad para analizar el califato de Córdoba, el emirato nazarí de Granada, el emirato de Sicilia, el Imperio romano oriental y la presencia otomana, todos ellos acontecimientos ocurridos en ese periodo. Parafraseando a González Ferrín, diré que Al-Ándalus no se explica con los marcos conceptuales propios de la historiografía medievalista y arabista actual, sino que $\mathrm{Al}$ Ándalus explica otra historia del sur de Europa y de la génesis del sistema mundial a partir de 1492, hasta ahora negada por las historiografías eurocéntricas y castellanocéntricas.

En este sentido, el historiador granadino José Enrique RuizDomèneq $(2017,176)$ afirma: "la grandeza de Al-Ándalus es que cambió al ritmo de la historia universal, no fuera de ella". De forma muy acertada, también Lampert-Weissig $(2010,40)$ plantea: "Lo que está en juego en cuanto a la cuestión de Al-Ándalus es una nueva forma de comprender la Europa medieval y la tradición occidental".

\section{Conclusiones provisionales: Al-Ándalus en la descolonización epistémica de Europa}

Según lo desarrollado, tanto el medievalismo como el arabismo han reproducido lógicas eurocéntricas que continúan represen- 
tando el pasado de la península ibérica en función de la experiencia de los territorios noroccidentales de Europa respecto a los del mundo árabe y musulmán, es decir, otorgando privilegio epistémico a las culturas occidentales y representando al sur de Europa en relación con su incorporación a los países occidentales del norte de Europa, o a los países árabes e islámicos.

Por otra parte, tanto la corriente decolonial latinoamericana como el reciente medievalismo poscolonial anglosajón han contribuido con acercamientos importantes que nos ponen ante un escenario de renovación intelectual en el campo de los estudios andalusíes, aunque deben ser observados con mirada crítica para evitar reproducciones mecánicas de dichas teorías. Las consecuencias teóricas y epistémicas alcanzan a reformular el papel del sur de Europa en la génesis del sistema mundial moderno colonial. Pensar Al-Ándalus como un territorio de guerra fronteriza respecto a África y el mundo árabe, pero también al Caribe y América Latina, nos permite reformular los marcos conceptuales de interpretación de la experiencia andalusí. Crear una enunciación desde la propia experiencia histórica de las sociedades del sur de Europa, y renovar las periodizaciones con las que se ordena históricamente el pasado de Europa nos permitirá superar las visiones medievalistas tradicionalistas. Estos son algunos de los retos a los que convoca la nueva discusión poscolonial para tratar la cuestión andalusí más allá de los legados del colonialismo europeo y de la hegemonía castellanocéntrica en las ciencias sociales españolas.

En cuanto a esta discusión, tanto Andalucía y el Estado español como el sur de Europa se pueden incorporar fácilmente desde perspectivas intelectuales propias y experiencias históricas diferenciadas. Al-Ándalus sigue siendo el gran centro de la discusión sobre el Mediterráneo occidental, así como la conexión entre la 'reconquista' y el 'descubrimiento'. Es, además, un campo de estudio estratégico para observar la génesis de procesos posteriores, como las conquistas coloniales, los proyectos imperiales, los nacionalismos hegemónicos, las formaciones económicas extractivas y la lógica de clasificacio- 
nes sociales y etnorraciales. En este sentido, el reto fundamental de las universidades y las ciencias sociales contemporáneas del sur de Europa es volver a pensar la experiencia histórica continental desde perspectivas no occidentalistas y no coloniales. Reinventar Europa desde un nuevo diálogo intelectual que la resitúe epistémicamente como parte del mundo y no sólo como centro de la experiencia histórica mundial. De esta forma, volver a pensar Europa junto al mundo es también volver a pensar el mundo más allá de la experiencia occidental.

\section{Referencias}

Abellán García, José Luis. 1993. “La polémica de Sánchez Albornoz con Américo Castro". En Sánchez-Albornoz a debate. Homenaje de la Universidad de Valladolid con motivo de su centenario, editado por Reyna Pastor de Togneri, Carlos Estepa Díez, José Ángel García de Cortázar y Ruiz de Aguirre, José Luis Abellán García y José Luis Martín Rodríguez, 45-52. Valladolid: Universidad de Valladolid.

Acién Almansa, Manuel. 1994. Entre el feudalismo y el islam: 'Umar Ibn Hafșunn en los historiadores, en las fuentes y en la historia. Jaén: Universidad de Jaén.

Altschul, Nadia R. 2009. "The Future of Postcolonial Approaches to Medieval Iberian Studies”. Journal of Medieval Iberian Studies 1 (1): 5-17. https://doi.org/10.1080/17546550802700244 ANZALDÚA, Gloria. 2016 [1987]. Borderlands/La frontera: La nueva mestiza. Madrid: Capitán Swing.

AzIzA, Mimoun. 2017. "Un orientalisme 'périphérique' : l'orientalisme espagnol face au passé arabo-musulman de l'Espagne”. Danubius 35 (2): 301-312.

Barbero, Abilio y Marcelo Vigil Pascual. 1994. La formación del feudalismo en la Península Ibérica. Barcelona: Crítica.

Barrios Aguilera, Manuel. 2007. La convivencia negada. Historia de los moriscos del Reino de Granada. Granada: Comares.

Bartlett, Robert. 2001. "Medieval and Modern Concepts of Race and Ethnicity". Journal of Medieval and Early Modern Studies 31 (1): 39-56. 
BRAUdel, Fernand. 2015. El Mediterráneo y el mundo mediterráneo en la época de Felipe II. Vol. 2. México: Fondo de Cultura Económica.

CaIro, Heriberto y Ramón Grosfoguel, eds. 2010. Descolonizar la modernidad, descolonizar Europa. Un diálogo Europa-América Latina. Madrid: Instituto de Estudios Políticos para América Latina y África.

Calderwood, Eric. 2018. Colonial Al-Andalus: Spain and the Making of Modern Moroccan Culture. Cambridge: Harvard University Press.

Castro, Américo. 1954. La realidad histórica de España. México: Porrúa.

Chakrabarty, Dipesh. 2008. Provincializing Europe: Postcolonial Thought and Historical Difference. Princeton: Princeton University Press.

Cohen, Jeffrey Jerome, ed. 2000. The Postcolonial Middle Ages. Nueva York: Palgrave Mcmillan. https://doi.org/10.1057/ 9780230107342

Coronil, Fernando. 1998. "Más allá del occidentalismo: hacia categorías geohistóricas no imperialistas”. En Teorías sin disciplina. Latinoamericanismo, poscolonialidad y globalización en debate, editado por Santiago Castro-Gómez y Eduardo Mendieta, 121146. México: Miguel Ángel Porrúa.

Corral Lafuente, José Luis. 2009. "La historia medieval en España: una reflexión a comienzos del siglo xxI". Imago Temporis, núm. 3, 408-417. https://raco.cat/index.php/ImagoTemporis/ article/view/209032/285428

Dagenais, John y Margaret Greer, eds. 2000. "Decolonizing the Middle Ages". Número especial, The Journal of Medieval and Early Modern Studies 30 (3).

DAvIES, Angela. 1981. Women, Race and Class. Nueva York: Random House.

Dussel, Enrique. 1983. Introducción a la filosofía de la liberación. $2^{\mathrm{a}}$ ed. Bogotá: Nueva América.

Dussel, Enrique. 1994. 1492: el encubrimiento del Otro. Hacia el origen del "mito de la modernidad". La Paz: Plural.

Dussel, Enrique. 2007. Política de la liberación. Historia mundial y crítica. Madrid: Trotta. 
Dussel, Enrique. 2008. "Meditaciones anti-cartesianas: sobre el origen del anti-discurso filosófico de la modernidad". Tabula Rasa, núm. 9, 153-197. https://doi.org/10.25058/20112742.344

FAls Borda, Orlando. 1987. Ciencia propia y colonialismo intelectual: los nuevos rumbos. Bogotá: Carlos Valencia.

FAnjul, Serafín. 2014. Al-Andalus contra España: la forja del mito. Madrid: Siglo XXI.

Fernández Parrilla, Gonzalo. 2018. "Disoriented Postcolonialities: With Edward Said in (the Labyrinth of) Al-Andalus". Interventions. International Journal of Postcolonial Studies 20 (2): 229-242. https://doi.org/10.1080/1369801x.2017.1403347

Galán SÁnchez, Ángel. 1991. Los mudéjares del Reino de Granada. Granada: Universidad de Granada.

GalcerÁn Huguet, Montserrat. 2016. La bárbara Europa. Una mirada desde el postcolonialismo y la descolonialidad. Madrid: Traficantes de Sueños.

Ganim, John M. 2016. Medievalism: Three Essays on Literature, Architecture and Cultural Identity. Nueva York: Pelgrave Macmillan.

García-Contreras, Guillermo. 2021. "Are Postcolonial Narratives Useful in Al-Andalus Archaeology?”. Anduli: Revista Andaluza de Ciencias Sociales, núm. 20, 179-199. https://doi.org/10.12795/ anduli.2021.i20.10

García-Contreras Ruiz, Guillermo, Luis Martínez Vázquez y Sonia Villar Mañas. 2012. “¿Prospectando los documentos? El análisis del territorio andalusí y la documentación escrita. Problemas, límites y propuestas a partir de tres casos de estudio". ArkeoGazte: Revista de arqueología-Arkelogia aldizkaria, núm. 2, 159-183. http://hdl.handle.net/10810/27925

GARCÍA FERNÁNDEZ, Javier. 2016. “Latifundio, capitalismo y colonialidad interna estructural (siglo XIII-XVII): estrategias teóricas para pensar históricamente el latifundio andaluz". Tabula Rasa, núm. 25, 283-313. https://doi.org/10.25058/20112742.85

GARCÍA FERNÁNDEZ, Javier. 2018a. "Descolonizando a Marx: cuatro tesis para pensar históricamente Andalucía”. Tabula Rasa, núm. 28, 197-228. https://doi.org/10.25058/20112742.n28.9

GARCía FERnÁNDEZ, Javier. 2018b. "O prelúdio à conquista do Caribe e da América: A formação da Andaluzia moderna como paradigma do sistema mundo moderno colonial. Olhares descoloniais a partir do sul da Europa”. Revista Brasileira do Caribe 19 (37): 
29-43. http://www.periodicoseletronicos.ufma.br/index.php/ rbrascaribe/article/view/11180

García FERnÁndeZ, Javier. 2019a. “¿Qué significa descolonizar Europa? Historia, cultura y descolonización de las ciencias sociales. Entrevistas a María Paula Meneses". Revista Internacional de Pensamiento Político 14: 557-565. https://doi.org/10.46661/ revintpensampolit.4836

GARCÍA FERNÁNDEZ, Javier. 2019b. Descolonizar Europa: ensayos para pensar históricamente desde el Sur. Madrid: Brumaria.

García Fernández, Javier. 2019c. "Diálogos tras dos décadas de descolonización epistémica: memorias y horizontes del pensamiento decolonial. Entrevista biográfica a Ramón Grosfoguel”. Transmodernity: Journal of Peripheral Cultural Production of the Luso-Hispanic World 9 (2). https://doi.org/10.5070/T492046327 García-FernándeZ, Javier. 2021. "Descolonización del conocimiento y pensamiento andaluz descolonial". Anduli: Revista Andaluza de Ciencias Sociales, núm. 20, 289-312. https://doi.org/10.12795/ anduli.2021.i20.16

García FernándeZ, Javier y Curro Moreno Colmenero. 2015. “Colonialidad y cuestión agraria en Andalucía”. En La década ganada en América Latina: una mirada analítica a las luchas populares/ Irabazitako hamarkada Latinoamerikan. Herri borrokei begirada analitikoa, coordinado por Unai Vázquez Puente y Luis Miguel Uharte Pozas, 279-287. Bilbao: Universidad del País Vasco.

García SANJUÁn, Alejandro. 2001. "La traducción de fuentes árabes andalusíes al castellano: balance y valoración”. Medievalismo: Boletín de la Sociedad Española de Estudios Medievales, núm. 11, 107122. https://revistas.um.es/medievalismo/article/view/51501 García Sanjuán, Alejandro. 2005. "La aportación de Claudio Sánchez-Albornoz a los estudios andalusíes". Revista de Historiografía, núm. 2, 143-153.

GARCía SANJuÁn, Alejandro. 2017. "Al-Andalus en la historiografía nacionalcatólica española: Claudio Sánchez-Albornoz”. eHumanista: Journal of Iberian Studies, núm. 37, 305-328.

García Sanjuán, Alejandro. 2018. Estudios críticos de historia de AlAndalus. Jerez de la Frontera: Peripecias Libros.

Gaunt, Simon. 2009. "Can the Middle Ages Be Postcolonial?”. Comparative Literature 61 (2): 160-176. https://doi. org/10.1215/00104124-2009-004 
González Alcantud, José Antonio. 2021. Qué es el orientalismo: el oriente imaginado en la cultura global. Córdoba: Almuzara.

GonZÁlez Alcantud, José Antonio y Sandra Rojo Flores. 2014. "La Alhambra de Granada: un fractal orientalista en clave poscolonial. Los puntos de vista local y árabe”. Estudios de Asia y África 49 (3): 693-722. https://estudiosdeasiayafrica.colmex.mx/index. $\mathrm{php} / \mathrm{eaa} / \mathrm{article} / \mathrm{view} / 2081$

González Casanova, Pablo. 2006. "Colonialismo interno (una redefinición)". En La teoría marxista hoy. Problemas y perspectivas, compilado por Atilio A. Borón, Javier Amadeo y Sabrina González, 409-434. Buenos Aires: Consejo Latinoamericano de Ciencias Sociales.

GonZÁlEz FERRÍn, Emilio. 2015. "La encrucijada del islam (y de la islamología)". Erebea: Revista de Humanidades y Ciencias Sociales 5: 71-88. https://doi.org/10.33776/erebea.v5i0.2686

GonzÁlez Ferrín, Emilio. 2019. Historia general de Al Ándalus. Europa entre Oriente y Occidente. Córdoba: Almuzara.

GONZÁLEZ JimÉNEZ, Manuel. 1988. En torno a los orígenes de Andalucía: la repoblación del siglo XIII. Sevilla: Universidad de Sevilla.

Grosfoguel, Ramón. 2008. "Hacia un pluriversalismo transmoderno decolonial". Tabula Rasa, núm. 9, 199-215. https://doi. org/10.25058/20112742.345

Grosfoguel, Ramón. 2011. "Racismo epistémico, islamofobia epistémica y ciencias sociales coloniales”. Tabula Rasa, núm. 14, 341355. https://doi.org/10.25058/20112742.431

Grosfoguel, Ramón. 2013. "Racismo/sexismo epistémico, universidades occidentalizadas y los cuatro genocidios/epistemicidios del largo siglo xvı". Tabula Rasa, núm. 19, 31-58. http:// ref.scielo.org/r6mbhm

Grosfoguel, Ramón. 2014. "Las múltiples caras de la islamofobia”. De Raíz Diversa. Revista Especializada en Estudios Latinoamericanos 1 (1): 83-114. https://doi.org/10.22201/ppela. 24487988e.2014.1.58208

Grosfoguel, Ramón. 2016. “Caos sistémico, crisis civilizatoria y proyectos descoloniales: pensar más allá del proceso civilizatorio de la modernidad/colonialidad”. Tabula Rasa, núm. 25, 153-174. https://doi.org/10.25058/20112742.79 
GRUZINSKI, Serge. 2016. La colonización de lo imaginario: sociedades indígenas y occidentalización en el México español. Siglos XVI-XVIII. México: Fondo de Cultura Económica.

GuHA, Ranajit. 1983. Subaltern Studies II: Writings in South Asian History and Society. Delhi: Oxford University Press.

GuiAnCE, Ariel. 2011. "La historiografía española y el medievalismo americano: Sánchez-Albornoz, Américo Castro y la construcción de la identidad nacional a través de la Edad Media”. En La influencia de la historiografía española en la producción histórica americana, dirigido por Ariel Guiance, 25-58. Madrid: Marcial Pons Historia.

GuICHARD, Pierre. 1976. Al-Andalus: estructura antropológica de una sociedad islámica en Occidente. Barcelona: Barral.

Hausberger, Bernd. 2018. Historia mínima de la globalización temprana. México: El Colegio de México. https://doi.org/10.2307/j. ctv6hp421

Hobsbawm, Eric J. 1998. La era del Imperio, 1875-1914. Traducido por Juan Faci Lacasta. Barcelona: Crítica.

Holsinger, Bruce W. 2002. "Medieval Studies, Postcolonial Studies, and the Genealogies of Critique". Speculum 77 (4): 1195-1227. https://doi.org/10.2307/3301217

Ladero Quesada, Miguel Ángel. 1969. Granada: Historia de un país islámico (1232-1571). Madrid: Gredos.

LAMPert-Weissig, Lisa. 2010. Medieval Literature and Postcolonial Studies. Edimburgo: Edinburgh University Press.

LANDER, Edgardo, comp. 2000. La colonialidad del saber: eurocentrismo y ciencias sociales. Perspectivas latinoamericanas. Buenos Aires: Consejo Latinoamericano de Ciencias Sociales.

LÓpez García, Bernabé. 2011. Orientalismo e ideología colonial en el arabismo español (1840-1917). Granada: Universidad de Granada.

López García, Bernabé. 2016. "Los arabistas españoles 'extramuros' del orientalismo europeo (1820-1936)”. Revista de Estudios Internacionales Mediterráneos, núm. 21, 107-117. https://doi. org/10.15366/reim2016.21.009

Malpica Cuello, Antonio. 2004. "Economía rural en el Reino de Granada. De la sociedad andalusí a las modificaciones castellanas". Chronica Nova. Revista de Historia Moderna de la Universidad de Granada, núm. 30, 265-316. https://revistaseug.ugr.es/ index.php/cnova/article/view/1895 
Manzano Moreno, Eduardo. 2006. Conquistadores, emires y califas. Los omeyas y la formación de al-Andalus. Barcelona: Crítica.

Marín, Manuela. 1992. "Arabistas en España: un asunto de familia”. Al-Qantara. Revista de Estudios Árabes 13 (2): 379-394. http:// hdl.handle.net/10261/18366

MARÍn, Manuela. 2009. "Orientalismo en España: estudios árabes y acción colonial en Marruecos (1894-1943)”. Hispania. Revista Española de Historia 69 (231): 117-146. https://doi.org/10.3989/ hispania.2009.v69.i231.101

MARín, Manuela. 2014. "Reflexiones sobre el arabismo español: tradiciones, renovaciones y secuestros". Hamsa. Journal of Judaic and Islamic Studies, núm. 1, 1-17. https://doi.org/10.4000/ hamsa. 855

Martínez Montávez, Pedro. 1994. Introducción a la literatura árabe moderna. Granada: Universidad de Granada.

Meneses, María Paula G. 2011. "Epistemologías del Sur: diálogos que crean espacios para un encuentro de las historias". En Formas-Otras. Saber, nombrar, narrar, hacer. IV Training Seminar de Jóvenes Investigadores en Dinámicas Interculturales, 31-41. Barcelona. Centro de Estudios y Documentación Internacionales de Barcelona. https://www.cidob.org/en/publications/ publication_series/monographs/monographs/formas_otras_saber_nombrar narrar hacer

MignoLo, Walter. 1995. “Occidentalización, imperialismo, globalización: herencias coloniales y teorías postcoloniales”. Revista Iberoamericana 61 (170-171): 27-40. https://doi.org/10.5195/ reviberoamer.1995.6392

Mignolo, Walter D. 2000. "La colonialidad a lo largo y a lo ancho: el hemisferio occidental en el horizonte colonial de la modernidad". En La colonialidad del saber: eurocentrismo y ciencias sociales. Perspectivas latinoamericanas, compilado por Edgardo Lander, 52-82. Buenos Aires: Consejo Latinoamericano de Ciencias Sociales.

Mignolo, Walter. 2003. Historias locales/diseños globales: colonialidad, conocimientos subalternos y pensamiento fronterizo. Madrid: Akal.

Mignolo, Walter. 2008. "Hermenéutica de la democracia: el pensamiento de los límites y la diferencia colonial". Tabula Rasa, núm. 9, 39-60. https://doi.org/10.25058/20112742.338 
Molina MartíneZ, Luis. 1992. "El arabista español ante las fuentes históricas". Al-Qantara: Revista de Estudios Árabes 13 (2): 445-456.

Pérez Flores, Larisa. 2017. "Islas, cuerpos y desplazamientos. Las Antillas, Canarias y la descolonización del conocimiento”. Tesis doctoral. Universidad de la Laguna. http://riull.ull.es/xmlui/ handle/915/19051

PÉREZ Flores, Larisa. 2018. "De Fanon a la interseccionalidad: neurosis, sexo y descolonización”. Atlántida. Revista Canaria de Ciencias Sociales, núm. 9, 107-128. https://doi.org/10.25145/j. atlantid.2018.09.006

Quijano, Aníbal. 2000. "Colonialidad del poder, eurocentrismo y América Latina". En La colonialidad del saber: eurocentrismo $y$ ciencias sociales. Perspectivas latinoamericanas, compilado por Edgardo Lander, 193-238. Buenos Aires: Consejo Latinoamericano de Ciencias Sociales.

Ríos Saloma, Martín F. 2011. La Reconquista. Una construcción bistoriográfica (siglos XVI-XIX). Madrid: Marcial Pons.

Ruiz-DomÈNEQ, José Enrique. 2017. "Al-Ándalus, ¿qué ocurrió, en qué orden y con qué resultados?”. eHumanista: Journal of Iberian Studies 37: 172-176.

SAID, Edward W. 2004. Orientalismo. Barcelona: Debolsillo.

SÁnchez Albornoz, Claudio. 1957. España. Un enigma histórico. Buenos Aires: Rialp.

SÁNCHEZ SAUS, Rafael. 2017. "Un lugar para Al-Andalus en la historia medieval de España”. eHumanista: Journal of Iberian Studies, núm. 37, 185-205.

Sousa SANTOS, Boaventura de. 2016. "Para uma nova visão da Europa: aprender com o Sul”. Sociologias 18 (43): 24-56. https://doi. org/10.1590/15174522-018004302

Sousa Santos, Boaventura de. 2019. El fin del Imperio cognitivo. La afirmación de las epistemologías del sur. Traducido por Álex Tarradellas. Madrid: Trotta.

Sousa Santos, Boaventura de y Bruno Sena Martins. 2018. "Socialismo, democracia e epistemologias do Sul. Entrevista com Boaventura de Sousa Santos". Revista Crítica de Ciências Sociais, Número especial, 9-54. https://doi.org/10.4000/rccs.7647

Sousa SANTos, Boaventura de y José Manuel Mendes, eds. 2017. Demodiversidad: imaginar nuevas posibilidades democráticas. Madrid: Akal. 
Thiong'o, Ngugi wa. 1992 [1987]. Decolonising the Mind: The Politics of Language in African Literature. Nairobi: East African Publishers.

Viguera Molins, María Jesús. 1992. Los reinos de taifas y las invasiones magrebies: (Al-Andalus del IX al XIII). Madrid: Mapfre.

Wallerstein, Immanuel, coord. 1996. Abrir las ciencias sociales: informe de la Comisión Gulbenkian para la reestructuración de las ciencias sociales. Traducido por Stella Mastrángelo. México: Siglo XXI.

WickHAM, Chris. 2009. Una historia nueva de la Alta Edad Media. Europa y el mundo mediterráneo, 400-800. Traducido por Tomás Fernández Aúz y Beatriz Eguibar. Barcelona: Crítica.

Javier García Fernández es licenciado en historia por la Universidad de Granada, máster en La España contemporánea en el contexto internacional por la Universidad Nacional de Educación a Distancia y doctor en sociología por el Centro de Estudios Sociales de la Universidad de Coimbra, con tesis doctoral realizada bajo la dirección del sociólogo portugués Boaventura de Sousa Santos.

$$
\begin{array}{r}
\text { https://orcid.org/0000-0001-7994-5477 } \\
\text { j.garcia.fer1987@gmail.com } \\
\text { javiergarcia@ces.uc.pt }
\end{array}
$$

